\title{
OS PROCESSOS METAFÓRICOS DO VOCABULÁRIO DA INFLAÇÃO NO BRASIL
}

\author{
Maria Eugenia Malheiros-Poulet
}

RESUMO: L'article fait l'analyse de la divulgation d'un phénomène économique brésilien aux années 80 - le combat à l'inflation - à travers la revue brésilienne Veja. L'utilisation de la métaphore par cet hebdomadaire realise une fonction à la foit éclaircissante et simplificatrice $d u$ discours téchnico-cientifique qui fait la médiation du sens entre les classes dirigeantes et la population qui souffre les effets de l'inflation: c'est grâce à l'emploi de la métaphore que le lecteur est persuadé du fait qu'il comprend et contrôle la situation. Cet acte persuasif et orienté finit par cacher le rôle négatif joué par le gouvernement en même temps qu'il produit l'illusion de liberté d'action.

PALAVRAS-CHAVE: discurso de vulgarização, análise lingüístico-pragmática, processos metafóricos, metáfora, estratégias interpretativas.

\section{INTRODUÇÃO}

Um estudo sobre a divulgação do vocabulário da inflação no Brasil requer primeiramente que situemos o contexto econômico do período estudado.

A crise econômica dos anos 80 foi ocasionada principalmente devido à enorme dívida externa (117 bilhões de dólares) com juros acumulados. Para cumprir com as obrigações da dívida externa o governo propõe planos econômicos sucessivos.

A partir de 1986, o governo Sarney decidiu tomar medidas drásticas contra a inflação (com a participação e o apoio massivo da população):

Sarney decreta a morte do cruzeiro, acaba com a correção monetária, congela os preços e abre uma luta de morte contra a inflação

(Veja, 5/3/86).

Foi igualmente neste período que a imprensa começou a ter uma grande importância no seu papel de divulgadora de mudanças econômicas e sociais: $O$ 
guia do Cruzado (Veja, 12/3/86).

Veja dirige-se a uma parte da população (os $30 \%$ das classes A, B e C) que pode lutar ou ter a ilusão de que luta contra a inflação e que tem condições (em diferentes níveis) de administrar o seu dinheiro: colocar o seu dinheiro no banco, seguir e tentar compreender os planos do governo, etc.

Entretanto, $70 \%$ da população (classe D e E) sofre as consequiências da crise e não pode lutar contra a inflação: só conhece a linguagem dos preços, dos salários e do desemprego.

A inflação não é somente assunto para economistas ou para a imprensa escrita. A linguagem da inflação pertence ao homem da rua, à dona de casa. É divulgada pela televisão (Rede Globo: o canal mais popular deste período e também o mais próximo do governo!).

Este estudo foi realizado com base em um corpus construído a partir da Revista Veja, no período de fevereiro de 1986 a fevereiro de 1990.

Sabendo-se, entretanto, que Veja não atinge e nem representa a opinião de todas as camadas sociais, deveremos igualmente procurar analisar o papel da imprensa como divulgadora das realidades quotidianas, dos implícitos culturais, políticos, das ideologias veiculadas, etc.

\section{OS PROCESSOS METAFÓRICOS}

A vulgarização apresenta-se como um conceito polissêmico e é por vezes sinônimo de divulgação ${ }^{1}$. Conservando o conceito de polissemia, extrapolaremos, dizendo que a metáfora situa-se no grau mais exagerado da vulgarização do discurso técnico-científico por ser, talvez, uma adaptação mais próxima do significado $^{2}$ de uma experiência vivida e portanto mais realista em nível do referente.

\section{Alguns aspectos da teoria da metáfora}

Para Lakoff "le système conceptuel humain est en grande partie structuré de manière métaphorique". (LAKOFF, 1986).

Esta figura é fonte de inúmeras teorias, desde a retórica clássica até a retórica moderna.

Vejamos alguns pontos específicos da teoria da metáfora, a partir dos quais desenvolveremos este estudo:

1) Seguindo Paul Ricoeur, analisaremos a referência do enunciado metafórico como "pouvoir de re-décrire la réalité" (RICOEUR, 1975).

\footnotetext{
${ }^{1}$ Galisson R. Recherche de lexicologie descriptive: banalisation lexicale. Paris, Nathan. 1978.

${ }^{2}$ Rijo da F. Lino, M. T. In: Colóquio Internacional: Língua Portuguesa: que futuro? Lisboa, nov. 1989. 100
} 



2) A metáfora traduz e até impõe uma maneira de ver, ligada às intenções do locutor.

3) Proporcionando uma certa visão do mundo, a metáfora adquire uma grande força persuasiva.

4) A metáfora veicula também uma apreciação implícita (salvo nos casos de metáfora fixa ou morta). Ela não é arbitrária, possui um semantismo orientado pela atualização de alguns semas específicos.

5) Sendo uma maneira de explicar a visão do mundo, a metáfora é utilizada para traduzir em linguagem corrente o que é abstrato e difícil de ser compreendido. Segundo Le Guern "c'est par la métaphore que les mystiques expriment l'inexprimable, qu'ils traduisent en langage, ce qui dépasse le langage". (LE GUERN, 1973).

\section{O papel da Revista Veja na utilização da metáfora}

A divulgação de um fenômeno econômico através da revista Veja será a matéria de nossa análise. Nesta apresentação vamos nos limitar a algumas observações sobre o emprego da metáfora a partir de uma análise lingüísticopragmática.

Vejamos como a imprensa tenta explicar, divulgar e simplificar todo o processo inflacionário, que já é bastante complexo até para os melhores economistas.

Como explicar por exemplo que, em 1986 com 56 mil cruzados, comprava-se um carro e que dois anos mais tarde, com esta mesma quantia, comprar-se-ia dois pneus?

Retomemos a citação de Le Guern (1973) modificando-a um pouco: é pela metáfora que a imprensa traduz em linguagem o que ultrapassa a própria linguagem.

Tentaremos assim demonstrar em que medida a metáfora empregada na imprensa pode explicar (interpretar) um fenômeno econômico complexo (decodificação de uma língua especializada) e ao mesmo tempo traduzir os efeitos da inflação sobre os brasileiros. 
A metáfora parte de dois sentidos literais da palavra inflação (o sentido dado pelos especialistas e o sentido dado e vivido pela população brasileira). É evidente que a utilização da metáfora é um dos recursos da linguagem jornalística, entre outros.

Não está ao nosso alcance, nem seria nosso objetivo neste momento, analisarmos a relação existente entre a economia governamental e os efeitos produzidos no povo brasileiro:

O que propomos neste estudo é um modelo de análise que parte da convergência de três visões sobre o processo inflacionário:

Visão dos especialistas - Visão da Revista Veja - Visão dos Leitores de $V e j a$, conforme é possível examinar no esquema que segue:

ESPECIALISTAS
Linguagem especializada das
classes dirigentes: ministros,
economistas, etc.
O termo científico e técnico
adquire seu valor específico
somente no discurso entre es-
pecialistas.
Mas: instabilidade dos planos
econômicos. Luta contra a in-
flação: conjunto de medidas e-
conômicas recomeçadas con-
tinuamente. Repetição do que
já foi proposto.

\begin{tabular}{|l|} 
IMPRENSA: Veja \\
Dupla fonte, dupla implicação. \\
Através da metáfora há a \\
mediatização dos dois sentidos \\
literais. A imprensa transforma \\
a informação para exagerá-la \\
ou para simplificá-la. \\
A difusão do fenômeno infla- \\
cionário ocasiona: \\
perda do valor da substância do \\
conteúdo da linguagem técnica \\
especializada. \\
Mas ela traduz também o in- \\
consciente coletivo (cf. metá- \\
fora do dragão). \\
A imprensa quer dar uma \\
impressão de clareza, tudo pa- \\
rece fácil e com isto ela desen- \\
volve uma argumentação ilu- \\
sionista.
\end{tabular}

| LEITORES

$30 \%$ da população brasileira teria condições de ler Veja. São os consumidores potenciais de Veja.

Esta parte da população vive a inflação através da

- perda do poder aquisitivo

- do desemprego

- da instabilidade econômica Isto tudo é representado pelo "Monstro" - o medo do irracional

Mas o leitor é persuadido de que compreende.

Devemos considerar, pois, os seguintes pontos:

- o estatuto e a função dos interlocutores;

- as intenções enunciativas (L);

- as estratégias de interpretação (D);

- os campos de referência (L/D);

- a situação de comunicação: as características espaço-temporais da interação lingüística (neste caso ligadas aos acontecimentos políticos): O efeito Sarney (os fiscais de Sarney), o efeito Collor (esperança? expectativa? decepção!!!).

\section{A força persuasiva da metáfora}

A difusão do processo inflacionário pode ser dirigida, orientada para que o 
leitor seja persuadido de que está compreendendo, que está controlando a situação. Os títulos de Veja são como receitas: Como proteger o seu dinheiro [...] (Veja, 6/8/86); Como investir o dinheiro com a volta da inflação (Veja, 14/1/87); Um guia para enfrentar a inflação (Veja, 31/8/88).

Para determinar as diferentes estratégias interpretativas, utilizaremos alguns elementos propostos por Ricoeur para analisar a metáfora. (RICOEUR, Paul. op. cit.).

A metáfora principal da inflação está fundamentada numa situação conflituosa (numa estrutura de conflito) onde há um adversário (a inflação) e uma vítima (a economia brasileira). A metáfora cria uma narrativa.

A inflação é representada como uma entidade seguidamente personificada, ela representa o adversário que age.

A economia é também muitas vezes personificada. Ela representa implicitamente o povo brasileiro como vítima, por relação metonímica (Outros tipos de metonímia surgem: uma cédula bancária eletrificada, uma moeda remendada).

Nesta situação de conflito há colaboradores que ajudam respectivamente o adversário e a vítima.

As entidades negativas representam as Forças do Mal como:

- a dívida externa;

- a dívida interna;

- a economia mal administrada;

- a pressão das camadas privilegiadas.

As entidades positivas representam as Forças do Bem, que agem para proteger a vítima, para lutar, para curar o doente. Mas o colaborador pode pedir sacrifícios para que a cura ou o resultado da luta seja eficaz. São as medidas governamentais contra a inflação; os diferentes planos econômicos: Plano Cruzado, Plano Cruzadinho, Plano Cruzado II, Plano Bresser (austeridade), Plano Feijão com Arroz (pela sua simplicidade, aqui é o próprio governo que utiliza uma linguagem metafórica, inspirada no quotidiano), Plano Cruzado Novo, etc.

Entretanto, a origem deste conflito está numa série de fatores (efeitos negativos causados pela inflação):

- desvalorizacão da moeda;

- perda do poder aquisitivo;

- aumento dos preços de maneira incontrolável.

A partir deste referente, estabelecido pela experiência vivida, cria-se a metáfora que acentua o caráter negativo (traços sêmicos) contido no sentido da palavra inflação.

Da metáfora a inflação é um adversário, surge uma série de outras metáforas derivadas:

1) Com a inflação estamos em estado de guerra:

[...] luta de morte contra a inflação (Veja, 5/3/86); A guerra das etiquetas (Veja, 12/3/86); A batalha do Cruzado (Veja, 19/3/86); O que há por trás da 
guerra dos preços (Veja, 2/4/86); Os inimigos do pacote (Veja, 30/4/86); Guerra dos preços (Veja, 22/6/88); A Guerra começou... A nação contra a inflação. Publicidade do Banco do Brasil (Veja, 1/2/89); O pagamento a prazo transforma-se numa forma de tortura [...] (Veja, 12/2/90).

2) A inflação é uma doença:

O choque da inflação (Veja, 12/3/86); Cirurgia sem dor... cortes no orçamento (Veja, 24/8/88); O choque de verão (Veja, 18/1/89); A agonia do Cruzado (Veja, 10/1/90); Os anticorpos (Veja, 10/1/90); Stress coletivo (Veja, 14/2/90).

3) A inflação é uma catástrofe:

O naufrágio dos preços, [...] dos investimentos (Veja, 14/1/87); tábuas da salvação (Veja, 31/8/88); O flagelo da inflação (Veja, 31/8/88).

4) A inflação é um jogo:

A cartada decisiva (Veja, 28/1/87); A aposta dos preços (Veja, 17/6/87); Jogo de cara ou coroa (Veja, 30/9/87); Zélia: o coringa de Collor (Veja, 17/1/90).

5) A inflação ligada à noção do tempo (e também à ecologia):

[...] dinheiro biodegradável, basta que fique um dia no bolso para que perca $2 \%$ do seu valor... (Veja, 14/2/90); Ao fazer do dinheiro uma mentira, Sarney transformou numa verdade literal a expressão tempo é dinheiro (Veja, 14/2/90).

6) A inflação é um dragão:

O monstro está solto (Veja, 13/5/87); O dragão irado (Veja, 28/12/88); $O$ dragão reclama uma dieta mais forte (Veja, 28/12/88).

Constatamos a importância da imagem para a análise da metáfora em nível linguiístico: em muitos exemplos é a representação icônica que produz a metáfora (cf. o monstro está solto).

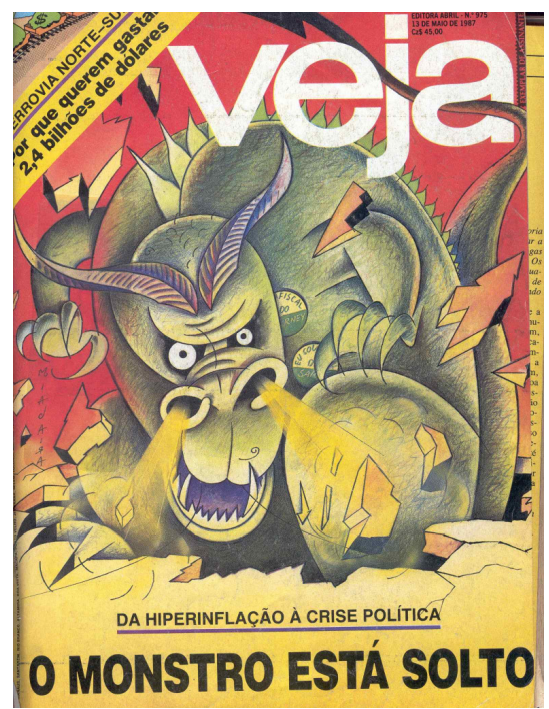


Observemos a metáfora do Dragão. A inflação é muitas vezes representada pela cauda do dragão, que serve para representar a curva da inflação.

Entre outras imagens associadas ao implícito cultural brasileiro, temos a figura de São Jorge combatendo o dragão - um dos elementos do sincretismo brasileiro (religião católica + crenças de origens africanas ou indígenas) - de onde surgem também metáforas derivadas: A macumba econômica, o vodu dos preços.

Mas a representação icônica nos descreve um dragão simpático, saído de um conto de fadas ou de um desenho animado (imagem associada aos contos tradicionais, vindos da Europa e do Oriente).

Por outro lado, São Jorge sairá vencedor desta luta: esperança implícita. A metáfora cria novas realidades, ela apresenta-se, pois, como uma maneira de controlar a situação: slogan de Sarney Está tudo sob controle.

\section{O implícito da metáfora}

A partir da metáfora a inflação é um adversário, podemos perceber que o governo situa-se na intersecção das duas forças contraditórias e apresenta-se como uma entidade dupla, bicéfala, ora representando os Forças do Bem, ora, as Forças do Mal.

Entretanto, quando se trata do aspecto negativo, esta relação permanece implícita.

A inflação é pois percebida como um elemento externo à política governamental, que se esforça em combatê-la. Mesmo quando é dito explicitamente que o culpado da inflação é o governo, há sempre referências a fatos passados (governo militar) ou futuros (Collor).

O papel negativo do governo é sempre ocultado. Esse tipo de metáfora dálhe uma ampla liberdade de ação.

A metáfora nesse caso não é somente uma maneira de perceber a realidade. Ela funciona como um ato persuasivo e orientado.

Representando uma nova realidade, poder de redescrever a realidade, a metáfora é a prova de que a inflação está integrada ao quotidiano.

A inflação destrói as referências econômicas, sociais e psíquicas, mas este monstro, que faz parte da vida quotidiana, é um monstro domesticado, que vive com os brasileiros.

Retomemos o nosso esquema inicial, focalizando o referente: 


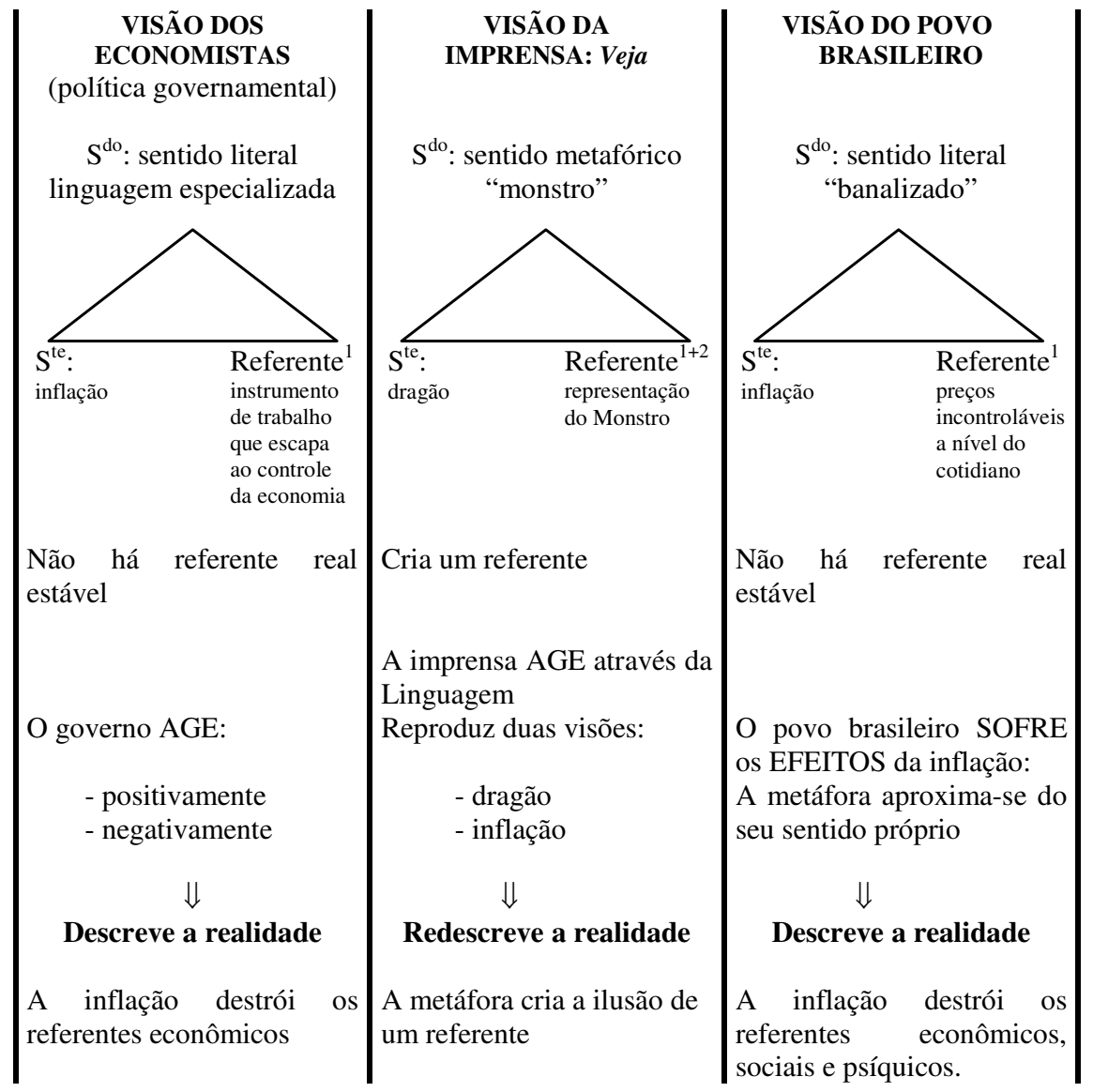

\section{CONSIDERAÇÕES FINAIS}

Se ultrapassarmos o período estudado, observamos que em 1994 a história recomeça mais uma vez... Seria a inflação um conto cíclico, que recomeça a cada vez, narrando sempre a mesma história?

Nessa narrativa quotidiana, a retórica do governo e das mídias trituram a linguagem, os fatos são mascarados e os significados confundidos. Mas as pessoas sentem a necessidade de acreditar; o discurso econômico, quer seja especializado ou metafórico, dá uma certa segurança. Além do discurso metafórico, a linguagem dos números, às vezes incompreensível, serve para encobrir o verdadeiro problema e exorcizar a realidade e o futuro incerto.

Entretanto, há também outras visões metafóricas da inflação, mais otimistas, como a do barulho das remarcadoras de preços, que o humorista 
comparou com o plec-plec das baterias de carnaval. Ou a visão do sambista que se inspira no drama da inflação para compor uma marcha de carnaval: Etiquetar, Etiquetar, Etiquetar... sem falar do futebol!

\section{BIBLIOGRAFIA}

GALISSON, R. Recherche de lexicologie descriptive: banalisation lexicate. Paris, Nathan, 1978.

LAKOFF, G.; JOHNSON, M. Metáforas de Ia vida cotidiana. Madrid, Cátedra, 1986.

LE GUERN, M. Sémantique de la métaphore et de la métonymie. Paris, Larousse, 1973.

RICOEUR, P. La métaphore vive. Paris, Seuil, 1975.

RIJO, da F.; UNO, M. T. Língua Portuguesa: que futuro? COLÓQUIO INTERNACIONAL, Lisboa, nov. 1989. 

Perspectiva da Análise do Discurso 
